\title{
A NEGAÇÃO DA CULTURA DIGITAL PELAS ESCOLAS E SUAS CONSEQUÊCIAS NO PROCESSO DE ENSINO APRENDIZAGEM
}

Irinaldo dos santos ${ }^{1}$

\section{RESUMO}

Este artigo aborda a negação da cultura digital pela escola, numa perspectiva de compreensão para o nosso sistema de ensino fazer uma reflexão diante a sua importância no processo de ensino aprendizagem. Nos mostra também alguns paradigma na educação e falta das políticas públicas votadas para formação continuada dos professores concernente as novas tecnologias da comunicação e informação e a sua contribuição, tanto no processo metodológico e pedagógico. Mostrando também aos educadores que as TICs é algo presente na vida de nossos educando, apesar da desigualdade corroborar para exclusão digital de muitos, a escola precisa trilhar um caminho que seja diferente a negação desta cultura.

Palavras Chaves: Cultura digital. Ensino aprendizagem. Políticas públicas. 


\section{INTRODUÇÃO}

Não resta dúvida de que, nos dias de hoje, a utilização de novas formas de interação on-line atende às novas necessidades dos alunos; o incentivo à aprendizagem ativa e significativa ao aluno já pode ser comprovada por meio de vários projetos já desenvolvidos em todo pais; é evidente o acesso rápido e eficiente na obtenção de informações relevantes e diversificadas e a melhoria da qualidade da comunicação entre professores e alunos são viabilizadas pelas ferramentas interativas. No entanto, as escolas ao invés de negar a cultura digital deve abraçar esta ferramenta quem vem colaborando de forma significativa no processo de ensino aprendizagem.

Hoje a tecnologia é útil ao aprendizado, pois o seu desconhecimento vem gerando no mundo atual o mesmo tipo de exclusão que sofre o analfabeto no mundo da escrita. E a exclusão da cultura digital formaremos cidadão analfabetos digitais e colocando 0 mesmo as margens da sociedade. Mas agora vem a seguinte pergunta, o que é necessário? Esta é uma pergunta difícil de ser respondida, pois depende do contexto, da realidade em que se vive e da autonomia de cada um. O que se pode afirmar, sem erro, é que é preciso entender que o essencial é acreditar no potencial cognitivo de cada um. "É essencial à descoberta da alegria do conhecimento, pois ela é à base da autonomia e da subjetividade".

Todos nós buscamos a tal sonhada autonomia e ela se diante da busca do conhecimento, as TICs nos propicia a tudo isso, desde que haja uma orientação por parte daqueles que são corresponsáveis por este processo da busca. A cultura digital colabora bastante para que isso aconteça de forma significativa e produtiva, em sua missão de comunicação e informação, basta-nos, atentar para esta mecanismo tão poderoso que há a nossa disposição.

Uma outra medida importante é não dar ouvidos aos mitos. A questão os computadores tomarão o lugar dos docentes? Vem sendo sempre colocada, o que faz com que se reforce a ideia de que o docente se recusa a inovar-se. Mas o que existe de verdade é a falta de conforto com o uso da tecnologia "nos ambientes educacionais, que é decorrente do escasso investimento governamental em políticas de formação e atualização do professor.

\footnotetext{
${ }^{1}$ Mestre em Ciências da Educação (FICS). Especialista no Ensino da Matemática (FJC). Especialista em Ciências da Educação (FAFI). Licenciado em Matemática (FTC). Professor da rede municipal de Serra do Ramalho - BA. E-mail: irinaldo.santos2@gmail.com
} 


\section{A NEGAÇÃO DA CULTURA DIGITAL PELA ESCOLA E SUAS CONSEQUÊNCIAS NO PROCESSO DE ENSINO APRENDIZAGEM}

O Brasil vivia, em 2002, a novidade das câmeras digitais e a popularização dos computadores, do acesso à internet e aos telefones celulares, que logo passariam a incorporar recursos para a troca de mensagens de texto e para a produção de fotos e vídeos. Jornais on-line, comunidades virtuais, mecanismos de busca, correio eletrônico e diversos outros serviços gratuitos na rede reconfiguravam inteiramente as práticas de comunicação e de sociabilidade. Os blogs colocavam-se como uma alternativa de informação independente, e discutia-se se a agilidade editorial dos blogueiros poderia realmente significar um golpe na hegemonia dos grandes veículos de comunicação.

Levando também a escola a compreender essa nova era da cultura digital para avançar administrativamente e em sua parte pedagógica. Campo perfeito para a democratização da informação e comunicação para assim desenvolver o processo de ensino aprendizagem em sua comunidade escolar.

Para o docente que vê na tecnologia uma forma de qualificar melhor suas práticas pedagógicas, é fundamental enxergar a realidade e principalmente lutar contra o discurso neoliberal paralisante que domina o meio educacional. É preciso conhecer as políticas equivocadas que fazem parte da história da utilização da informática na educação no Brasil.

Evitar a resistência pelo desconhecimento é entender que o computador e o software educacional, seja ele qual for, é uma ferramenta auxiliar do processo de aprendizagem do aluno. Uma aula ruim é ruim com ou sem tecnologia, e uma aula boa será sempre boa independentemente da tecnologia utilizada. Isto significa dizer que: a qualidade está no conteúdo que deve ser bem planejado e disponibilizado de modo que seja possível a aquisição de conhecimento pelo aluno.

A mídia deve ser adequada ao conteúdo, pois este vem em primeiro lugar. A tecnologia não cria ambientes que prescindem do professor, é preciso que o professor tome para si a tarefa de projetar o material didático e a pedagogia a ser utilizada no processo de ensino. Não inovar na produção do material didático e nas metodologias de aprendizagem, significa deixar a cargo de profissionais da área tecnológica, a tarefa de ensinar por meio de software desenvolvido sem o viés da educação, o que de um modo geral vem ocorrendo com frequência. 
É fato que os perfis dos profissionais, que hoje planejam software educacional, são de programadores de computador, que desconhecem a área educacional. $\mathrm{O}$ planejamento de um bom projeto necessita da formação de uma equipe multidisciplinar, cujos participantes complementam 0 projeto utilizando suas competências específicas e diversificadas.

Hoje muito se fala da necessidade de se educar para os meios, ou seja, educar para o uso da ferramenta própria do mundo digital. Mas muito se fala e pouco se faz, a respeito da preparação de professores na orientação do aluno diante desses novos conceitos e novas relações, que surgem nesse mundo tecnológico. É nesse contexto que informações provenientes de diversas direções chegam a indivíduos cuja realidade não Ihes permite desenvolver capacidade crítica de análise, competência fundamental para evitar o colapso de valores importantes para o desenvolvimento da cidadania, da ética e da solidariedade. Por meio dessa abordagem, o uso da tecnologia integra novos saberes à prática educacional proporcionando ao professor uma maior capacidade crítica de sua ação pedagógica e um leque maior de possibilidades na busca pelo interesse dos seus alunos.

"Globalização" e trabalho docente: no enredo das tecnologias seja a globalização, objeto dos estudos de Torres (1998, p.28), caracterizada como construção ideológica, seja, como quer alguns, posta como conceito explicativo de uma nova ordem mundial, um aspecto desta realidade não pode ser ignorado: a educação como um todo e o trabalho docente, em especial, estão sendo reconfigurados.

Diante da realidade atual, não adianta as escolas negar a cultura digital, tão presente na vida de nossos alunos, tendo em vista, a mesma é uma ferramenta que irá auxiliar o desenvolvimento técnico pedagógico do professor(a) que fazem uso desse recurso da comunicação e informação. Mas na verdade há um contra ponto, as escolas negam a seus educando este recurso e o tem como um empecilho, no processo de ensino aprendizagem a sua interferência de forma negativa em sua formação. Tudo acontece por falta de informação de toda comunidade escolar que por sua vez utiliza destes recursos em suas residências e não permite que o mesmo seja utilizado nas escolas. Segundo o ex-secretário executivo do Ministério da Cultura, Alfredo Manevy (In: SAVAZONI; COHN, 2009, p. 36), em entrevista, "ele entendia a cultura digital não como uma tecnologia, mas como um sistema de valores, de símbolos, de práticas e de atitudes". E ele vai além quando afirma: 
Eu entendo o homem não apenas como um animal econômico, mas também como um animal político e simbólico, que é um ponto de partida que o digital aborda. Então eu vejo a cultura digital como uma tecnologia sem dúvida nenhuma, uma etapa da tecnologia, mas fundamentalmente um sistema de práticas e valores que está em disputa permanente na vida contemporânea.

Observando a forma grandiosa da relevancia das TICs, nos diversos campos de atuação na sociedade, entende-se que a mesma tem interferido no comportamento social de tudo que há, seja no setor produtivo, na cultura, na educação e na economia. No entanto negar esta cultura digital pelo proceso de ensino aprendizagem é condenar toda uma geração.

De qualquer modo, as relações entre discurso e mudança social precisam ser objeto de atenta análise política, com o fim dar conta de novos clichês que, circulando, contribuem para a produção de um imaginário o qual faz com que uma interpretação particular apareça como sendo a necessária, ao sustentar a legitimação e a fixação de sentidos hegemônicos.

Vale lembrar que, do ponto de vista discursivo, ideologia corresponde a hegemonia de sentido. O sentido hegemônico das TIC aponta para o primado da dimensão técnica, apagando as questões de fundo. Em se tratando da sua incorporação educacional, parece não haver espaço para a análise dos seus modos e sentidos.

Na perspectiva maniqueísta de "plugados ou perdidos", quaisquer objeções podem ser alvo da desqualificação que marca o segundo grupo. Enquanto isso, no primeiro, as discussões podem ser travadas a partir de questões como as diferenças entre aprendizagem cooperativa e colaborativa, ou entre construtivismo e construcionismo (Papert, 1993), nos limites da esfera dita pedagógica, sem remeter às suas dimensões econômicas, políticas e sociais.

Neste contexto, é importante verificar a afirmação de um "novo paradigma", recorrente no site do MEC, ou paradigma emergente, em geral associado ao afastamento das objetivações supostamente marcadas pela simplicidade, em direção à complexidade (Morin, 1998). É inegável a hegemonia do movimento de virtualização do ensino, na perspectiva de e learning, cuja tradução mais comum tem sido "educação a distância via Internet": uma forma de aprendizagem em que a mediação tecnológica é destacada, nos mais diversos "ambientes de aprendizagem".

\section{TRABALHO E FORMAÇÃO DOCENTE}

Em outras palavras, na perspectiva da "globalização" e do "globalitarismo", termo cunhado por Ramonet (1999) para dar conta da espécie de ditadura do pensamento 
único que regula a construção ideológica, a escola deve romper com a sua forma histórica presente para fazer frente a novos desafios. A pretensão, neste artigo, é analisar as determinações (concretas e pressupostas) e os sentidos (hegemônicos e em disputa por hegemonia) dessa reconfiguração, tomando por base os discursos que introduzem e justificam as atuais políticas públicas voltadas para a formação de professores.

No movimento de reconfiguração de trabalho e formação docente, outro aspecto parece constituir objeto de consenso: a possibilidade da presença das chamadas "novas tecnologias" ou, mais precisamente, das tecnologias da informação e da comunicação (TIC). Essa presença tem sido cada vez mais constante no discurso pedagógico, compreendido tanto como o conjunto das práticas de linguagem desenvolvidas nas situações concretas de ensino quanto as que visam a atingir um nível de explicação para essas mesmas situações que vivenciamos em cada comunidade escolar.

Em outras palavras, as TIC têm sido apontadas como elemento definidor dos atuais discursos do ensino e sobre o ensino, ainda que prevaleçam nos últimos. Atualmente, nos mais diferentes espaços, os mais diversos textos sobre educação têm, em comum, algum tipo de referência à presença das TIC no ensino. Entretanto, a essa presença têm sido atribuídos sentidos tão diversos que desautorizam leituras singulares. Assim, se aparentemente não há dúvidas acerca de um lugar central atribuído às TIC, também não há consenso quanto à sua delimitação.

Lévy (1999) afirma que, no limite, as TIC estão postas como elemento estruturante de um novo discurso pedagógico, bem como de relações sociais que, por serem inéditas, sustentam neologismos como "cibercultura". No outro extremo, o que as novas tecnologias sustentam é uma forma de assassinato do mundo real, com a liquidação de todas as referências, em jogos de simulacros e simulação (Baudrillard, 1991).

Para Moran, (2004) no entremeio, podem constituir novos formatos para as mesmas velhas concepções de ensino e aprendizagem, inscritas em um movimento de modernização conservadora, ou, ainda, em condições específicas, instaurar diferenças qualitativas nas práticas pedagógicas. Em síntese, a presença das TIC tem sido investida de sentidos múltiplos, que vão da alternativa de ultrapassagem dos limites postos pelas "velhas tecnologias", representadas principalmente por quadrode-giz e materiais impressos, à resposta para os mais diversos problemas educacionais ou até mesmo para questões socioeconômico-políticas. 
Nas palavras de Mattelart (2002, p. 9), a segunda metade do século XX foi marcada pela "formação de crenças no poder miraculoso das tecnologias informacionais". Mesmo que, em princípio, pareça ingênuo, este último movimento está inscrito em um modo de objetivação das TIC inextricavelmente ligado à concepção de "sociedade da informação".

Sendo assim, compreendem que as novas tecnologias da comunicação, veio para estabelecer uma nova ordem de comunicação e informação na sociedade, comunidade e etc, não adianta, em plena a contemporaneidade querermos impedir ou excluir essa ferramenta que veio para ficar. O que temos que fazer é nos aliar e não nos alienar, pois é algo presente na vida de toda comunidade escolar. Entendese também que a nossa sociedade é diversa e desigualdade social está presente, no entanto, há aqueles que ainda encontram-se a margem desse processo da cultura digital. Por conta disso há de se pensar uma política pública eficaz para então fazer inclusão digital dos mesmos.

Quando falamos de políticas públicas na educação é algo pertinente as esferas governamentais deste país, levar as escola públicas e privadas o acesso gratuito da informação e comunicação, pensado na qualidade da educação. Alguns professores também se enquadram nesta exclusão por resistir e pensar que as TICs poderá substitui-lo num futuro bem próximos, no entanto há diversos paradigmas a serem quebrados. Por isso a importância de uma formação continuada dos professores para quebrar este e outros paradigmas que o faz ver a tecnologia como uma inimiga e não como uma aliada de sua prática pedagógica e evolução no processo de ensino aprendizagem.

\section{A Utilização das Novas Tecnologias na Educação}

Estudos demonstram que a utilização das novas tecnologias de informação e comunicação (NTICs), como ferramenta, traz uma enorme contribuição para a prática escolares em qualquer nível de ensino. Essa utilização apresenta múltiplas possibilidades que poderão ser realizadas segundo uma determinada concepção de educação que perpassa qualquer atividade escolar.

É importante salientar que, desde o início da década de 90, as escolas públicas de vários estados têm sido equipadas com um verdadeiro arsenal de tecnologias: TV Escola, vídeo-escola, centrais de informática, etc. Todos esses projetos têm a pretensão de ensinar com o apoio das máquinas e assim melhorar a prática pedagógica. Certamente tais tecnologias têm auxiliado, em algum momento, o 
processo de ensino e talvez o de aprendizagem, mas o resultado tem sido pouco observável na prática e a educação formal continua essencialmente inalterada.

Para LOING (1998), a introdução das NTICs na educação deve ser acompanhada de uma reflexão sobre a necessidade de uma mudança na concepção de aprendizagem vigente na maioria das escolas atualmente.

Segundo LITTO (1992), o atual sistema educacional é um espelho do sistema industrial de massa, onde os alunos passam de uma série a outra, numa sequência de matérias padronizadas como se fosse uma linha de montagem industrial. Os conhecimentos acumulados são despejados em suas cabeças; alunos com maior capacidade para absorção de fatos e comportamento submisso são colocados em uma trilha mais veloz, enquanto outros são colocados na trilha de velocidade mediana.

\section{CONSIDERAÇÕES FINAIS}

Para o docente que vê na tecnologia uma forma de qualificar melhor suas práticas pedagógicas, é fundamental enxergar a realidade e principalmente lutar contra o discurso neoliberal paralisante que domina o meio educacional. É preciso conhecer as políticas equivocadas que fazem parte da história da utilização da informática na educação no Brasil.

Evitar a resistência pelo desconhecimento é entender que o computador e o software educacional, seja ele qual for, é uma ferramenta auxiliar do processo de aprendizagem do aluno. Uma aula ruim é ruim com ou sem tecnologia, e uma aula boa será sempre boa independentemente da tecnologia utilizada. Isto significa dizer que: a qualidade está no conteúdo que deve ser bem planejado e disponibilizado de modo que seja possível a aquisição de conhecimento pelo aluno.

A mídia deve ser adequada ao conteúdo, pois este vem em primeiro lugar. A tecnologia não cria ambientes que prescindem do professor, é preciso que o professor tome para si a tarefa de projetar o material didático e a pedagogia a ser utilizada no processo de ensino. Não inovar na produção do material didático e nas metodologias de aprendizagem, significa deixar a cargo de profissionais da área tecnológica, a tarefa de ensinar por meio de software desenvolvido sem o viés da educação, o que de um modo geral vem ocorrendo com frequência.

É fato que os perfis dos profissionais, que hoje planejam software educacional, são de programadores de computador, que desconhecem a área educacional. $\mathrm{O}$ planejamento de um bom projeto necessita da formação de uma equipe 
multidisciplinar, cujos participantes complementam o projeto utilizando suas competências específicas e diversificadas.

Este trabalho não só apresentou os aspectos constituintes da cultura digital, como refletir sobre o papel dessa versão de cultura, adaptada ao cenário virtual, enquanto elemento sob o qual também interage a educação a distância.

É importante analisar também que após tamanha investigação dos conceitos que envolvem o que é a cibercultura, foi possível perceber que houve todo um movimento histórico e de ação humana, como que "preparadores de terreno" para o que seria a cultura digital que conhecemos hoje. É visível a importância do movimento humano, a todo instante, pelo legado de sobrevivência, empreendendo esforços, alterando comportamentos e fazendo história.

De certa forma, parafraseando o autor Herlander Elias, tudo o que Da Vinci, Edison, e, pode-se acrescentar, Morus, sonharam, tornar-se-ia realidade muitos e muitos anos depois, quando o homem, a partir do seu campo de ação, transforma sua realidade e a de seu semelhante.

Conclui-se assim que a cultura digital em qualquer definição que possa ser dada, constitui-se, em essência, de compartilhamento, desterritorialização, racionalização, unificação e autonomia.

\section{REFERÊNCIAS:}

ALVES, N. Imagens de tecnologias nos cotidianos das escolas, discutindo a relação"localuniversal". In: ROMANOWSKI et al. (Org.). Conhe- 1199 Educ. Soc., Campinas, vol. 25, diversidade, mídias e tecnologias na educação. Curitiba: Champagnat, 2004.

BARRETO, R.G.; LEHER, R. Trabalho docente e as reformas neoliberais. In: OLIVEIRA, D.A. (Org.). Reformas educacionais na América Latina e os trabalhadores docentes. Belo Horizonte: Autêntica, 2003.

BAUDRILLARD, J. Simulacros e simulação. Lisboa: Relógio d'Água, 1991. Revisado por Editor do Webartigos.com

CUNHA, Cybelle Regina Carvalho da; PADILHA, Maria Auxiliadora Soares. A inclusão digital e social de jovens na cibercultura: um diálogo contemporâneo possível? III Simpósio Nacional ABCiber - Dias 16, 17 e 18 de Novembro de 2009 - ESPM/SP Campus Prof. Francisco Gracioso.

MOURA, A. Geração Móvel: um ambiente de aprendizagem suportado por tecnologi as móveis para a "Geração Polegar", 2010. Disponível em: http://adelinamouravitae.com.sapo.pt/gpolegar.pdf. Acesso em: 27 jan. 2014. 
SANTOS. Irinaldo. Uso das novas tecnologias da informação e comunicação como ferramenta no processo de ensino aprendizagem nas escolas da sede do município de Serra do Ramalho - Ba. Dissertação de Mestrado. Dissertação de Mestrado em Ciências da Educação - Faculdad Interamericana de Ciências Sociales, na Cidade de Assunção Paraguaio, 2019.

TRAXLER, J. Defining, discussing and evaluating mobile learning: The moving finger writes and having writ. The International Review of Research in Open and Distance Learning. 2007. Disponível em: <http://www.irrodl.org/index.php/irrodl/article/view/346> Acesso em: 27 jan. 2014.

UNESCO. Policy Guidelines for Mobile Learning. 2013. Disponível em: http://unesdoc.unesco.org/images/0021/002196/219641E.pdf>. Acesso em: 28 jan. 2014. 